Research Paper

\title{
Anti-inflammatory Effects of the Natural Compounds Cortex Phellodendri and Humulus japonicus on Pelvic Inflammatory Disease in Mice
}

\author{
Yeonsu Oh${ }^{1}$, Yong-Soo Kwon², Bae Dong Jung ${ }^{1 凶}$ \\ 1. College of Veterinary Medicine \& Institute of Veterinary Science, Kangwon National University, Chuncheon, 24341, Republic of Korea; \\ 2. College of Pharmacy, Kangwon National University, Chuncheon, 24341, Republic of Korea. \\ $\triangle$ Corresponding author: Bae Dong Jung, DVM, PhD, College of Veterinary Medicine \& Institute of Veterinary Science, Kangwon National University, \\ Chuncheon, 24341, Republic of Korea. Tel: +82-33-250-8674; Fax: +82-33-259-5625; E-mail: bdjung@kangwon.ac.kr \\ (c) Ivyspring International Publisher. This is an open access article distributed under the terms of the Creative Commons Attribution (CC BY-NC) license \\ (https://creativecommons.org/licenses/by-nc/4.0/). See http://ivyspring.com/terms for full terms and conditions.
}

Received: 2017.02.12; Accepted: 2017.06.18; Published: 2017.07.18

\begin{abstract}
Pelvic inflammatory disease (PID) is an inflammatory and/or infectious disorder of the upper female genital tract, including the uterus, fallopian tubes, and adjacent pelvic structures, that may spread upward to the peritoneum. Currently available treatment options have presented to produce adverse effects of various degrees, such as increased antimicrobial resistance and a limited effective duration of hormones. In the study, the Cortex Phellodendri (CP) and Humulus japonicus (HJ) among natural compounds that are believed to present biological activities with fewer side effects were tested in a PID animal model. The results suggested that the administration $C P$ and $H J$ reduced clinical signs, inflammatory cytokine expression as well as secretion in uterine tissue, and neutrophil infiltration into the tissue.
\end{abstract}

Key words: Pelvic inflammatory disease, Cortex Phellodendri, Humulus japonicus, anti-inflammation.

\section{Introduction}

Traditionally, the Cortex Phellodendri and Humulus japonicus have been used to alleviate several symptoms, such as heat, dampness, and toxicity. Cortex Phellodendri (CP) is derived from the dried trunk bark of Phellodendron amurense Rupr. and contains a number of alkaloids (e.g., berberine, palmitine, and phellodendrine) that are known to exert multiple pharmacological effects [3]. The methanolic extract of $\mathrm{CP}$ has been shown to inhibit gene expression and the production of proinflammatory proteins in LPS-stimulated microglia [4] and to have neuroprotective and anti-inflammatory activities in a neuronal dysfunction model [5], although the underlying mechanisms remain unclear. Humulus japonicus (HJ), belonging to the Cannabaceae family is a perennial herb that commonly grows in Korea and China and is imported for ornamental purposes in Western countries [6]. Previous studies have indicated that the extract of $\mathrm{HJ}$ possesses potential anti-aging properties via antioxidative [6], antitumor [7-9], antituberculosis [9] and antibacterial effects [10,11].

Pelvic inflammatory disease (PID) is an inflammatory and/or infectious disorder of the upper female genital tract, including the uterus, fallopian tubes, and adjacent pelvic structures, that may spread upward to the peritoneum [1, 2]. PID is one of the most serious complications of sexually transmitted diseases and the frequent uterine infections following abnormal parturitions in both women and animals, especially cows and horses. This disease directly causes economic losses because of resultant infertility, increased culling for failure to conceive, reduced production, and expenditures for drug treatments [12]. Although drugs, including antibiotics and hormones, are available for the treatment of PID, they produce adverse effects of various degrees, such as increased antimicrobial resistance and a limited effective duration of hormones [13]. Therefore, clinicians have turned to natural compounds that are 
believed to present biological activities with fewer side effects. Natural compounds, including oriental herbs, provide an immeasurable wealth of active molecules, and a great number of new drugs originated from these compounds [14]. The history of using medicinal herbs to ameliorate or treat numerous symptoms and diseases dates back thousands of years in various cultures [6]. In this study, $\mathrm{CP}$ and $\mathrm{HJ}$, which are known to have anti-inflammatory activities, were selected to determine whether they could be viable treatment options for PID, using a previously established PID animal model [12]. To the best of our knowledge, the potential alleviating effects of these herbs on PID have not been studied. Therefore, the purpose of this study is to investigate whether $\mathrm{CP}$ or $\mathrm{HJ}$ regulates inflammatory responses to mitigate PID using clinical, biochemical and immunopathological evaluations.

\section{Materials and Methods}

\section{Materials}

Lipopolysaccharide (LPS, Salmonella enterica serotype enteritidis), pregnant mare serum gonadotropin (PMSG) and antibodies for $\beta$-actin were purchased from Sigma-Aldrich (St. Louis, MO, USA). Hydrochloric acid was purchased from Yakuri Pure Chemicals (Kyoto, Japan). Dulbecco's Modified Eagle Medium (DMEM) and fetal bovine serum (FBS) were purchased from HyCloneTM (Logan, UT, USA) and Penicillin-Streptomycin Solution was purchased from WELGENE Inc. (Daegu, Republic of Korea). Antibodies for interleukin-1 $\beta$ (IL-1 $\beta$ ) were purchased from R\&D Systems (Minneapolis, MN, USA), and TNF-a was purchased from Cell Signaling Technology (Boston, MA, USA).

\section{Animals}

Female C57BL/6J mice (8-10 weeks) weighing 20-22 g were purchased from Nara Biotech (Seoul, Korea), maintained under a 12:12-h light-dark cycle in a temperature and humidity controlled room (24 \pm 5 ${ }^{\circ} \mathrm{C} ; 50 \pm 10 \%$ ) and fed a standard laboratory diet and water ad libitum. All experimental procedures were performed in accordance with the guidelines established by the Kangwon National University
Institutional Animal Care and Use Committee (KW-160314-1).

\section{Preparation of methanolic extracts of CP and HJ}

Dried $\mathrm{CP}$ and $\mathrm{HJ}$ were purchased from A Healing Nature (Pyeongchang, Republic of Korea). The CP and HJ were air-dried, after which, $300 \mathrm{~g}$ of each sample was cut into small pieces and extracted twice with $3 \mathrm{~L}$ of $80 \%$ methanol in a reflux condenser for $24 \mathrm{~h}$. The $\mathrm{CP}$ and $\mathrm{HJ}$ extracts were filtered through Whatman No. 1 filter paper and concentrated using a rotary vacuum evaporator, yielding $70 \mathrm{~g}(\mathrm{CP})$ and $51 \mathrm{~g}$ $(\mathrm{HJ})$. Finally, the $\mathrm{CP}(1 \mathrm{~g})$ and $\mathrm{HJ}(1 \mathrm{~g})$ extracts were each dissolved in saline $(1 \mathrm{ml})$ for i.c. administration.

\section{Experimental design}

Animals were randomly distributed into 4 groups: Cortex Phellodendri supplemented and PID group [CP-PID], Humulus japonicus supplemented and PID group [HJ-PID], PID group for a positive control [PID] and mock-treated negative control group [(-) CTL]. Either CP $(25 \mu \mathrm{l})$ or $\mathrm{HJ}(25 \mu \mathrm{l})$ extract was i.c. administered twice, once at 2 hours and once at 4 hours before PID was initially induced with $\mathrm{HCl}$ treatment, as described below.

To induce PID, as previously described [12], the animals were administered i.c. initially with $\mathrm{HCl}(1 \mathrm{~N})$, followed by four doses of LPS (50 mg/ kg), one dose every 2 hours, starting 2 hours after $\mathrm{HCl}$ injection. In the PID groups, $100 \mu \mathrm{l}$ of PMSG (7.5 IU per mouse) were administered 2 days before the experiment to induce proceptivity. Control mice received saline alone.

At 10 hours after initial inoculation, mice were sacrificed by incubation in a $\mathrm{CO}_{2}$ gas chamber at 2 $\mathrm{L} / \mathrm{min}$ for 3 to 5 minutes followed by cervical dislocation, and then uterine tissue samples were collected.

\section{Clinical evaluation}

The mice were monitored every 2 hours until the end of the experiment for clinical sign assessment according to the criteria shown in Table 1. The observers were blinded to the treatment status of the mice.

Table 1. Clinical sign scoring criteria

\begin{tabular}{llll}
\hline Clinical signs & Score & & \\
\cline { 2 - 4 } & 0 & 1 & 2 \\
\hline $\begin{array}{l}\text { Ruffled fur } \\
\text { Movement }\end{array}$ & $\begin{array}{l}\text { Normal } \\
\text { Normal }\end{array}$ & $\begin{array}{l}\text { Mild; ruffled fur }<30 \% \text { of the body } \\
\text { Mild; reduced movement and activity }<30 \%\end{array}$ & $\begin{array}{l}\text { Moderate; ruffled fur }<60 \% \text { of the body } \\
\text { Moderate; reduced movement and } \\
\text { activity }<60 \%\end{array}$ \\
$\begin{array}{llll}\text { Eye condition } \\
\text { Responsiveness }\end{array}$ & Normal & Mild; eye closed and discharge $<30 \%$ & $\begin{array}{l}\text { Moderate; eye closed and discharge }<60 \% \quad \text { Severe; eye closed and discharge }>60 \% \\
>60 \%\end{array}$ \\
\hline
\end{tabular}


Table 2. Histopathological lesion criteria

\begin{tabular}{|c|c|c|c|c|}
\hline \multirow{2}{*}{ Histopathology } & \multicolumn{4}{|l|}{ Score } \\
\hline & 0 & 1 & 2 & 3 \\
\hline Inflammation & $\begin{array}{l}\text { No sign of } \\
\text { inflammation }\end{array}$ & $\begin{array}{l}\text { Low leukocyte infiltration }(<30 \% \\
\text { of the field) }\end{array}$ & $\begin{array}{l}\text { Moderate leukocyte infiltration } \\
(<60 \% \text { of the field) }\end{array}$ & $\begin{array}{l}\text { Severe leukocyte infiltration( }>60 \% \\
\text { of the field) }\end{array}$ \\
\hline $\begin{array}{l}\text { Necrosis/ } \\
\text { Degeneration }\end{array}$ & Normal & $\begin{array}{l}\text { Mild necrosis or degeneration } \\
(<30 \% \text { of the field })\end{array}$ & $\begin{array}{l}\text { Moderate necrosis or degeneration } \\
(<60 \% \text { of the field) }\end{array}$ & $\begin{array}{l}\text { Severe necrosis or degeneration } \\
(>60 \% \text { of the field) }\end{array}$ \\
\hline $\begin{array}{l}\text { Congestion/ } \\
\text { Hemorrhage }\end{array}$ & Normal & $\begin{array}{l}\text { Mild congestion or hemorrhage } \\
(<30 \% \text { of the field) }\end{array}$ & $\begin{array}{l}\text { Moderate congestion or } \\
\text { hemorrhage }(<60 \% \text { of the field })\end{array}$ & $\begin{array}{l}\text { Severe congestion or hemorrhage } \\
(>60 \% \text { of the field) }\end{array}$ \\
\hline
\end{tabular}

\section{Preparation of positive control}

As described previously [12], RAW 264.7 cells were grown in DMEM supplemented with $10 \%$ FBS, 2 $\mathrm{mM}$ L-glutamine, $100 \mathrm{U} / \mathrm{mL}$ penicillin and 100 $\mathrm{mg} / \mathrm{mL}$ streptomycin at $37^{\circ} \mathrm{C}$ with $5 \% \mathrm{CO}_{2}$. The cells ( $5 \times 10^{5}$ cells $/ \mathrm{mL}$ ) were cultured in the presence of LPS for 2 hours in 12-well plates. The protein extracts were used as a positive control.

\section{Western blot analysis}

Tissues were homogenized in lysis buffer containing 10\% SDS and a protease inhibitor cocktail (A.G. Scientific Inc., CA, USA). Lysates were clarified by $12,000 \mathrm{rpm}$ centrifugation at $4{ }^{\circ} \mathrm{C}$ for $20 \mathrm{~min}$. Proteins were electrophoresed, transferred to nitrocellulose membranes and probed overnight with specific antibodies against $\beta$-actin , IL- $1 \beta$, or TNF- $\alpha$, as described previously [15]. Immunoblots were washed extensively and probed with the appropriate horseradish peroxidase-conjugated secondary antibodies. Bands were visualized using Pierce ${ }^{\circledR}$ ECL Plus Western Blotting Substrate (Lumigen, Inc. Southfield, MI, USA).

\section{Cytokine Determination}

According to the previous study [12], the pro-inflammatory cytokines were determined from uterine mucosa. The protein extracts were isolated by homogenization of uterine tissue segments $(50 \mathrm{mg}$ tissue $/ \mathrm{mL}$ ) in $50 \mathrm{mmol} / \mathrm{L}$ Tris- $\mathrm{HCl}, \mathrm{pH} 7.4$, with 0.5 $\mathrm{mmol} / \mathrm{L}$ dithiothreitol and $10 \mathrm{~g} / \mathrm{mL}$ of a protease inhibitor cocktail (Sigma). Samples were centrifuged at $30,000 \times \mathrm{g}$ for 20 minutes and stored at $-70{ }^{\circ} \mathrm{C}$ until cytokine determination. Cytokine levels in the uterine tissue protein extracts were measured by specific sandwich enzyme-linked immunosorbent assays using capture/biotinylated detection antibodies for IL-1 $\beta$ and TNF- $\alpha$ from R\&D Systems (Minneapolis, $\mathrm{MN}$, USA) according to the manufacturer's recommendations.

\section{Histopathological evaluation}

As previously described [12], at the end of the experiment, all mice were humanely euthanized and their uteruses were excised. A portion was fixed in $10 \%(\mathrm{w} / \mathrm{v})$ neutral buffered formalin for 24 to 48 hours, processed routinely and embedded in paraffin wax. Sections $(4 \mu \mathrm{m})$ were stained with hematoxylin and eosin (H\&E) for light microscopic examination. For the morphometric analysis of histopathological lesion score, three sections of each sample were randomly selected and six microscopic fields of each section were examined "blindly", according to the criteria shown in Table 2 and the number of neutrophils per unit area $\left(0.25 \mathrm{~mm}^{2}\right)$ was determined. To obtain quantitative data, histological slides containing lesions were analyzed using the NIH Image J 1.43 m Program (http://rsb.info.nih.gov/ij).

\section{Statistical analysis}

Summary statistics were calculated for all of the groups to assess the overall quality of the data, including normality. Continuous data (cytokine levels) were analyzed with a one-way analysis of variance (ANOVA) followed by pairwise testing using Tukey's adjustment as a posthoc test. Discrete data (clinical evaluation and histopathological lesion score) were analyzed by Chi-square and/or Fisher's exact tests. A value of $P<0.05$ was considered significant.

\section{Results}

\section{Clinical evaluation}

The most commonly observed clinical signs were hunched back with ruffled hair and closed eyes, with progressively more parametric clinical signs presented after the initial induction of PID with $\mathrm{HCl}$, especially in the PID group. The CP-PID and HJ-PID groups began to show clinical signs at 4 hours after the initial inoculation, but rapidly entered remission between 8 and 10 hpi. The mean clinical sign scores were significantly lower in the CP-PID and HJ-PID groups $(P<0.001)$ than the PID group but higher than the $(-)$ CTL group $(P<0.05)$. The mean clinical sign scores were not significantly different between the CP-PID and the HJ-PID groups (Figure 1).

\section{Inflammatory cytokine expression on uterine tissue}

To investigate the inflammatory cytokine expression levels, IL-1 $\beta$ and TNF- $\alpha$ were evaluated in uterine tissues by Western blot analysis, and the 
results showed that no cytokines were detected in the uterine tissues from the (-) CTL group and strong inflammatory cytokine expression was present in the PID group. Both the CP-PID and HJ-PID groups presented lower levels of cytokine expression than the PID group (Figure 2).

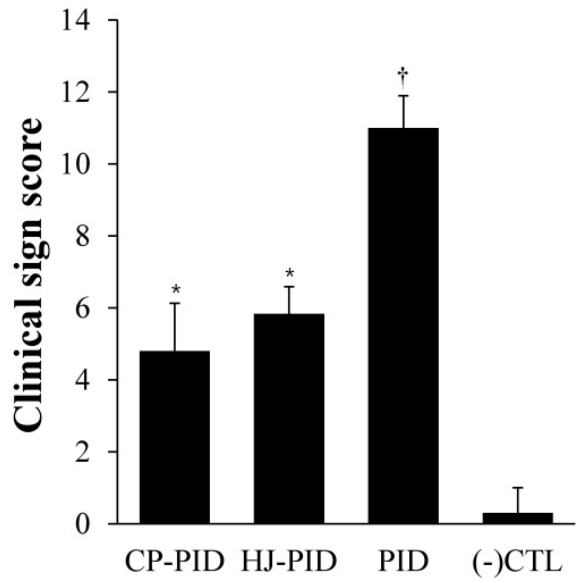

Figure 1. Mean values of clinical sign scoring. Indicates significantly more serious clinical signs in the PID positive control group LPS compared with treatment groups and the negative control group $(P<0.001)$. *Indicates significantly higher clinical sign scores than the other groups $(P<0.05)$.

Treatment with uterus

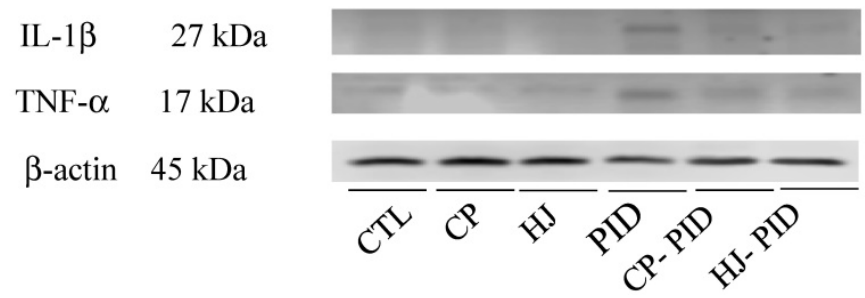

Figure 2. Changes in cytokine expression in uterine tissues with or without treatments. The IL-1 $\beta$ and TNF- $\alpha$ expression levels clearly increased in uterine tissues from the PID groups compared with the CP-PID and HJ-PID groups.

\section{Determination of inflammatory cytokines in uterine tissue}

$\mathrm{CP}$ or $\mathrm{HJ}$ treatment (the CP-PID and HJ-PID groups) significantly reduced the IL-1 $\beta$ level in uterine tissues $(P<0.001)$ compared with the PID group, but the levels were not lower than the (-) CTL group. Additionally, the TNF-a level of the CP-PID group was significantly reduced compared with the PID group $(P<0.001)$ and the HJ-PID group $(P<0.05)$ and was not significantly different than that of the $(-)$ CTL group (Figure 3).

\section{Histopathological lesion score}

Uterine tissue lesions in the PID group were detected by the infiltration of neutrophils, epithelial cell necrosis and degeneration, and congestion and hemorrhage, as previously described [12]. In the treatment groups (the CP-PID and HJ-PID groups) with the natural compounds, slight histopathological lesions, including congestion-related edema and negligible infiltration of neutrophils were observed.

A.

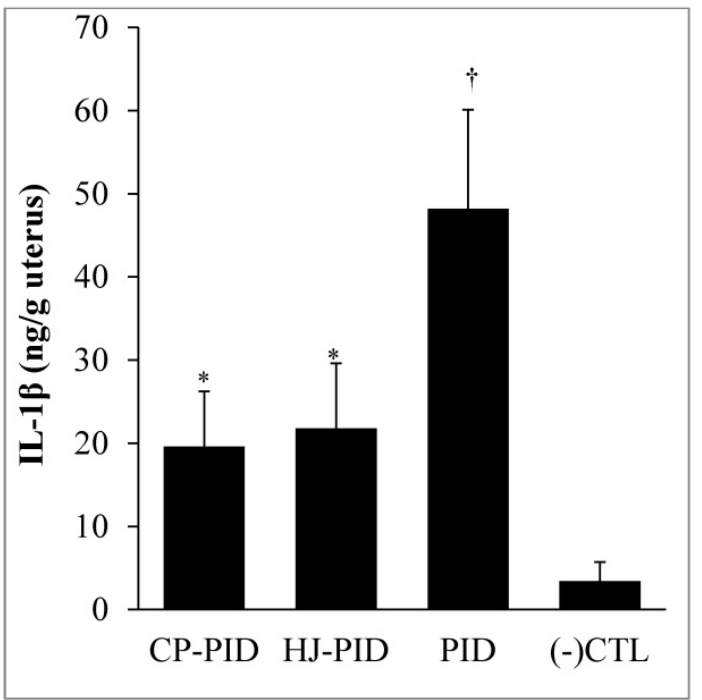

B.

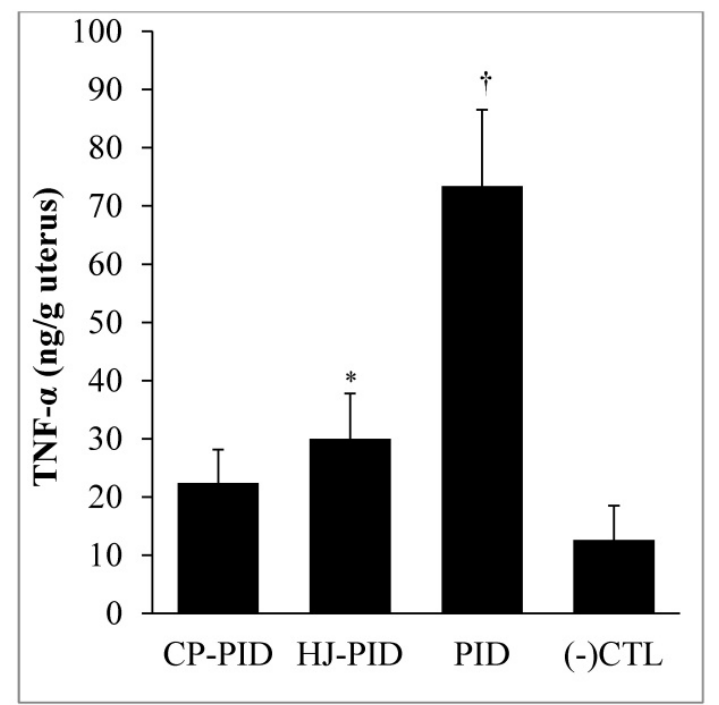

Figure 3. Inflammatory cytokines measured by ELISA in the uterine tissues of different experimental groups and a normal control. Indicates significantly higher inflammatory cytokine levels in the uterine tissues of the PID group than other groups $(P<0.001)$. *Indicates significantly different cytokine levels in the uterine tissues compared with the other groups $(P<0.05)$. ELISA: enzyme-linked immunosorbent assay.

The scores of uterine lesions and the number of infiltrated neutrophils were significantly higher in the PID group $(P<0.001)$ than other groups by intragroup comparison. The HJ-PID group presented significantly higher lesion scores $(P<0.05)$ than the CP-PID and (-) CTL groups (Figure 4). The number of infiltrated neutrophils were significantly higher $(P<$ $0.05)$ in the HJ-PID and CP-PID groups than (-)CTL group (Figure 5). 


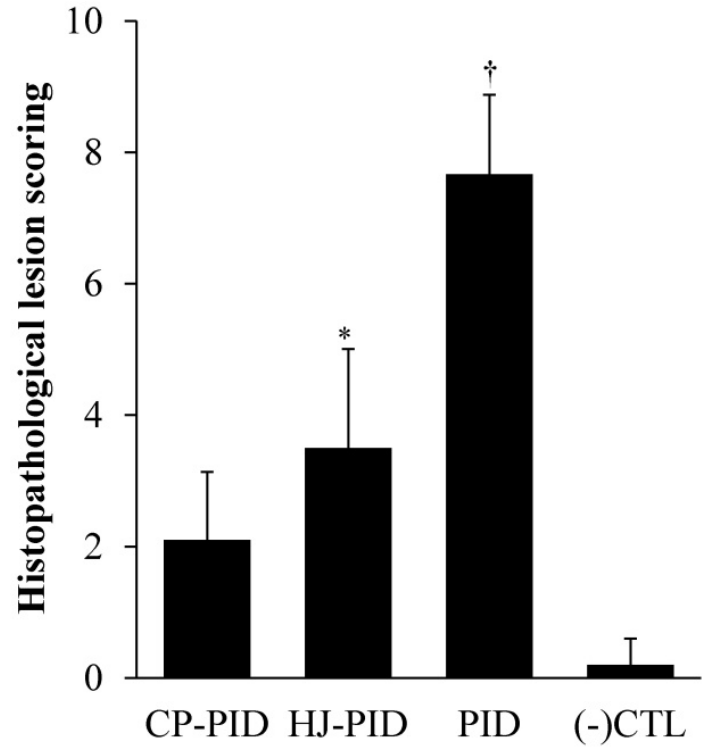

Figure 4. Histopathological scoring in different experimental groups. Indicates significantly higher histopathological scores in the PID group than those in the other groups $(P<0.001)$. *Indicates significantly different histopathological scores in the HJ-PID group than those in the other groups $(P<0.05)$.

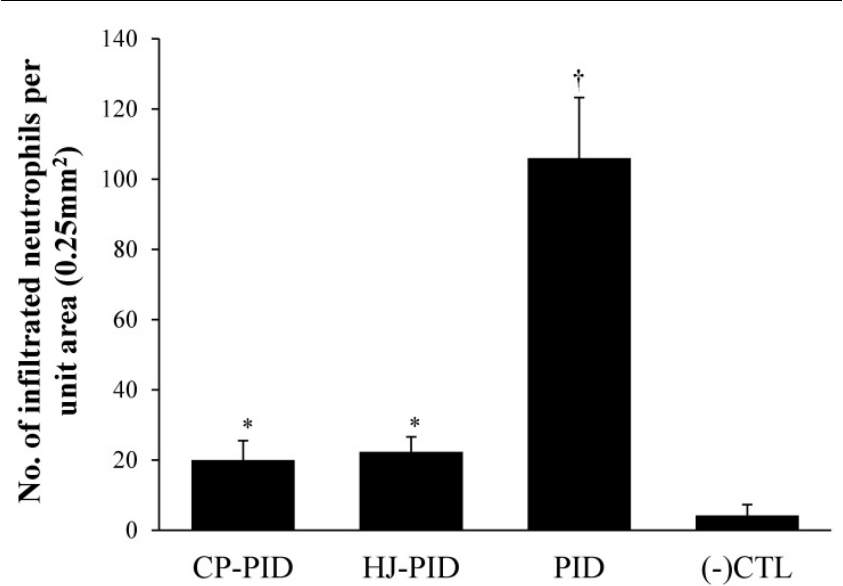

Figure 5. Number of infiltrated neutrophils per unit area $\left(0.25 \mathrm{~mm}^{2}\right)$ in uterine tissue of different experimental groups. I Indicates a significantly increased number of neutrophils in the PID group $(P<0.001)$ * Indicates s significantly increased number of neutrophils in the CP-PIC and HJ-PID groups compared with the negative control group $(P<0.05)$

\section{Discussion}

We studied effective alternative treatment options for PID by employing the medicinal herbs CP and $\mathrm{HJ}$, which have been used for centuries in Chinese traditional medicine for the treatment of various inflammatory conditions, as well as various clinical problems. While the products used in this study have various anti-inflammatory and anti-oxidant effects, including anti-aging effects, it remains uncertain whether they are effective treatments for PID. PID involves serious complications of genital health status in both humans and animals, especially in domestic animals.
Clinically, low abdominal pain is the main presenting symptom in women with PID, and the disease manifests in different ways, including endometritis, pelvic peritonitis, tubal abscess, and salpingitis [Yang et al., 2014]. Additionally, PID directly causes with economic losses because of resultant infertility, increased culling for failure to conceive, reduced production, and expenditures for drug treatments [12]. Treatment of PID focuses on the relief of acute symptoms, eradication of current infections, and minimization of the risk of long-term sequelae. These sequelae include chronic pelvic pain, ectopic pregnancy, and tubal factor infertility, among others [Romero et al., 2004]. Active interventions with remedies aid in the management of patients and improve compliance, but therapy with antibiotics alone is not enough successful [Liu et al., 2012] and includes the risk of antibiotic resistance and residual contamination of the environment.

There are no recommended alternative treatments for some forms of PID, and the use of antimicrobials has been documented with varied results. Moreover, when paromomycin, one of the chemotherapeutic agents used for infective PID, was administered intravaginally, vulval pain and mucosal ulceration, which may facilitate opportunistic infections, were reported [Dunne et al., 2003]. Natural substances or crude herbal medications exhibit many positive effects, including antimicrobial activity, in the veterinary field. Natural herbal supplements improved the growth rate, egg production and feed intake in layers, and gut microbiome and serum IgG in broilers (Hong et al., 2001; Ryu 1999; Woo 2007) and promoted the growth rate and serum immunoglobulin in pigs (Kwon 2003).

When the medicinal herbs $\mathrm{CP}$ or $\mathrm{HJ}$ were administered into mouse uteruses induced with PID, various inflammatory aspects of the animals were reduced, without any adverse clinical signs. The treatments alleviated clinical signs and reduced inflammatory cytokine expression in the uterine tissue. The CP-PID and HJ-PID groups secreted proinflammatory cytokines through uterine tissues significantly less than the non-treated PID group, and the results of the histopathological lesion scores strongly supported this result. Overall, the results suggest that the medicinal herbs $\mathrm{CP}$ and $\mathrm{HJ}$ are effective therapeutic options for PID, and to the authors' knowledge, this is the first report to describe $\mathrm{CP}$ and $\mathrm{HJ}$ as potential alternate therapeutic treatments for PID. In conclusion, regarding the PIDs as complicated diseases or symptoms, the results suggest that clinicians can use medicinal herbs as possible alternative therapeutic options, although additional studies concerning the active ingredients of 
the herbs, the mechanisms involved in reducing inflammation, and other factors of treatment are required.

\section{Acknowledgements}

This research was supported by the Bio-industry Technology Development Program (Grant No. 112130-3) funded by the Ministry for Food, Agriculture, Forestry and Fisheries of the Republic of Korea

\section{Competing Interests}

The authors have declared that no competing interest exists.

\section{References}

1. Choi YY, Kim MH, Han JM, Hong J, Lee TH, Kim SH, Yang WM. The anti-inflammatory potential of Cortex Phellondendron in vivo and in vitro: Down-regulation of NO and iNOS through suppression of NF- $\mathrm{KB}$ and MAPK activation. Int Immunopharma. 2014; 19: 214-20.

2. Mao YF, Li YQ, Zong L, You XM, Lin FQ, Jiang L. Methanol extract of Phellodendri cortex alleviates lipopolysaccharide-induced acute airway inflammation in mice. Immunopharmacol Immunotoxicol. 2010; 32: 110-5.

3. Lee B, Sur B, Shim I, Lee H, Hahm DH. Phellodendron amurense and its major alkaloid compound, berberine ameliorates scopolamine-induced neuronal impairment and memory dysfunction in rats: a Korean study. Korean J Physiol Pharmacol. 2012; 16: 79-89.

4. Sung B, Chung JW, Bae HR, Choi JS, Kim CM, Kim ND. Humulus japonicus extract exhibits antioxidative and anti-aging effects via modulation of the AMPK-SIRT1 pathway. Exp. Therapeutic medicine. 2015; 9: 1819-26.

5. Yu BC, Yang MC, Lee KH, Kim KH, Choi SU and Lee KR. Two new phenolic constituents of Humulus japonicus and their cytotoxicity test in vitro. Arch Pharm Res. 2007; 30: 1471-5.

6. Lee YR, Kim K, Lee SH, Kim MY, Park HJ and Jeong HS. Antioxidant and antitumor activities of methanolic extracts from Humulus japonicas: a Korean study. Korean J Food \& Nutrition. 2012; 25: 357-61.

7. Park SW, Kim SH and Chung SK: Antimutagenic effects and isolation of flavonoids from Humulus japonicus extract: a Korean study. Korean J Food \& Nutrition. 1995; 27: 897-901.

8. Hong M, Son E, Lee $\mathrm{S}$, et al: Anti-mycobacterial effects of the extract of Humulus japonicus: a Korean study. Korean J Food \& Nutrition. 2014; 46: 949.

9. Park SW, Woo CJ, Chung SK and Chung KT: Antimicrobial and antioxidative activities of solvent fraction from Humulus japonicus: a Korean study. Korean J Food \& Nutrition. 1994; 26: 464-70.

10. Duarte R, Fuhrich D, Ross JDC. A review of antibiotic therapy for pelvic inflammatory disease. Int J Antimicrb Agent. 2015; 46: 272-7.

11. Ross J, Judlin P, Jensen J. 2012 European guideline for the management of pelvic inflammatory disease. Int J STD AIDS. 2014; 25: 1-7.

12. Oh Y, Lee J, Kim HC, Hahn TW, Yoon BI, Han JH, Kwon YS, Park JJ, Koo DB, Rhee KJ, Jung BD. Establishment of HCl-LPS-induced pelvic inflammatory disease model. J Vet Sci. 2016; 17(3): 413-19.

13. Mari G, Iacono E, Toni F, Predieri PG, Merlo B. Evaluation of the effectiveness of intrauterine treatment with formosulphathiaxole of clinical endometritis in postpartum dairy cows. Theriogenology. 2012; 78: 189-200.

14. Vieira P de B, Giordani RB, Macedo AJ, Tasca T. Natural and synthetic compound anti-Trichomonas vaginalis: an update review. Parasitol Res. 2015; 114(4):1249-61.

15. Rhee KJ, Lee CG, Kim SW, Gim DH, Kim HC, Jung BD. Extract of Ginkgo Biloba ameliorates streptozotocin-induced type 1 diabetes mellitus and high-fat diet induced type 2 diabetes mellitus in mice. Int J Med Sci. 2015; 12(12): 987-94.

16. Yang SF, Wu TF, Tsai HT, Lin LY, Wang PH. New markers in pelvic inflammatory disease. Clinica Chimica Acta. 2014; 431: 118-24.

17. Romero R, Espinoza J, Mazor M. Can endometrial infection/inflammation explain implantation failure, spontaneous abortion, and preterm birth after in vitro fertilization? Fertil Steril. 2004; 82(4):799-804.

18. Liu K, Fogg L. Use of antibiotics alone for treatment of uncomplicated acute appendicitis: A systemic review and meta-analysis. Surgery. 2011; 150(4): 673-83.

19. Dunne RL, Dunn LA, Upcroft P, O'Donoghue PJ, Upcroft JA. Drug resistance in the sexually transmitted protozoan Trichomonas vaginalis. Cell Research. 2003; 13(4): 239-49.

20. Hong SJ, Namkung H, Paik IK. Effects of herbal products (Miracle20) on the performance, nutrient digestibility, small intestinal microflora and immune response in broiler chickens. J Anim Sci Technol. 2001; 43: 671-80.
21. Ryu KS, Song GS. Effects of feeding angelica gigas byproducts on performance and meat quality of Korean native chicks. Korean J Poult Sci. 1999; 26: 261-5.

22. Woo KC, Kim CH, NamGung Y, Paik IK. Effects of supplementary herbs and plant extracts on the performance of broiler chicks. Korean J Poult Sci. 2007; 34: 43-52.

23. Kwon OS, Kim IH, Kim JH, Hong JW, Min BJ, Lee WB, Shon KS. The effects of dietary herbal plant mixture on growth performance, nutrient digestibility, serological changes and carcass characteristics in finishing pigs. J Korea Acad Industr Coop Soc. 2003; 4: 334-40. 